\title{
A Case of Olfactory Groove Meningioma Presenting Anosmia
}

\author{
Seong Phill Moon, Joo Hyun Jung, Seon Tae Kim and Il Gyu Kang \\ Department of Otolaryngology-Head and Neck Surgery, Gachon University of Medicine \& Science, Graduate School of Medicine, \\ Incheon, Korea
}

후각소실로 나타난 후구 부위의 뇌수막종 1 예

문성필 · 정주현 · 김선태 · 강일규

가천의과학대학교 의학전문대학원 길병원 이비인후과학교실

\author{
Received January 17, 2011 \\ Revised March 31, 2011 \\ Accepted April 11, 2011 \\ Address for correspondence \\ Il Gyu Kang, MD \\ Department of Otorhinolaryngology- \\ Head and Neck Surgery, \\ Gachon University \\ of Medicine and Science, \\ Graduate School of Medicine, \\ 1198 Guwol-dong, Namdong-gu, \\ Incheon 405-760, Korea \\ Tel $+82-32-460-2757$ \\ Fax +82-32-467-9044 \\ E-mail eyik@gilhospital.com
}

The common causes of anosmia include sinonasal disorder, post-upper respiratory infection, trauma and chemicals. Intracranial tumor also frequently cause anosmia, so it is not easy to diagnose an intracranial tumor in patients who present with no definite related symptoms other than anosmia. Therefore, otolaryngologists should focus their attention on these disorders when they see patients with anosmia. We have experienced a case of olfactory groove menigioma presenting with only anosmia. We herein report this case with a brief review of the literature.

Korean J Otorhinolaryngol-Head Neck Surg 2011;54:431-4

Key Words Anosmia $\cdot$ Olfactory $\cdot$ Groove $\cdot$ Meningioma.

\section{서 론}

후각장애의 원인은 비·부비동 질환, 상기도 감염, 두부 손 상, 화학적 손상, 노령, 내분비 대상 이상, 종양, 선천성 이상 등 다양한 원인에 의해 발생할 수 있다. 이중 비·부비동 질 환 및 상기도 감염, 두부 외상에 의한 경우는 흔히 접할 수 있으며, 병력청취 및 이학적 검사 및 방사선 검사로 진단이 가능하다. 그러나 두개내종양으로 인한 후각장애의 경우, 두 통 및 신경학적 이상이 나타나지 않고 후각장애만 호소하는 경우가 드물게 있으므로 후각장애가 있을 시 두개내종양을 진단하기는 쉽지 않다.

두개내종양 중 가장 흔한 뇌수막종은 전체 원발성 두개내 종양의 13 26\%를 차지하는 양성 종양이며, 두개 내 어디서 나 발생가능하나 뇌 기저부에서 흔하게 발생하는 것으로 알 려져 있다.1) 뇌수막종의 여러 증상으로는 경련, 시야감소, 삼
킴 어려움, 반신마비 및 후각소실 등이 있다. 하지만 후각구 부(olfactory groove) 뇌수막종은 후각장애와 연관이 있을 수 있으나 종양과 관련된 다른 증상이 잘 나타나지 않고 크 기가 작을 경우에 증상이 없어 초기 진단이 쉽지 않다. ${ }^{2)}$

저자들은 내원 3개월 전부터 후각소실을 보인 35세 여자 환자에서 비강내 이학적 검사상 특이 소견이 없었지만 후각 소실의 가장 흔한 원인인 비·부비동 질환을 배제하기 위해 시행한 부비동 전산화 단층촬영에서 우연히 발견된 뇌 병변 에서 시행한 뇌 자기공명영상 촬영에서 뇌수막종이 확인된 1 예를 문헌고찰과 함께 보고하는 바이다.

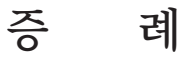

35세 여자환자가 3개월 전부터 시작된 후각소실을 주소로 내원하였다. 후각 소실의 흔한 원인인 비·부비동 질환을 감 
별하기 위해 시행한 이학적 검사상 비강을 관찰한 결과 비강 내용종 소견은 보이지 않았으며 화농성 비루도 관찰되지 않 았다. 또한 비중격 상부 및 상비갑개 내측, 후열 등에도 특이

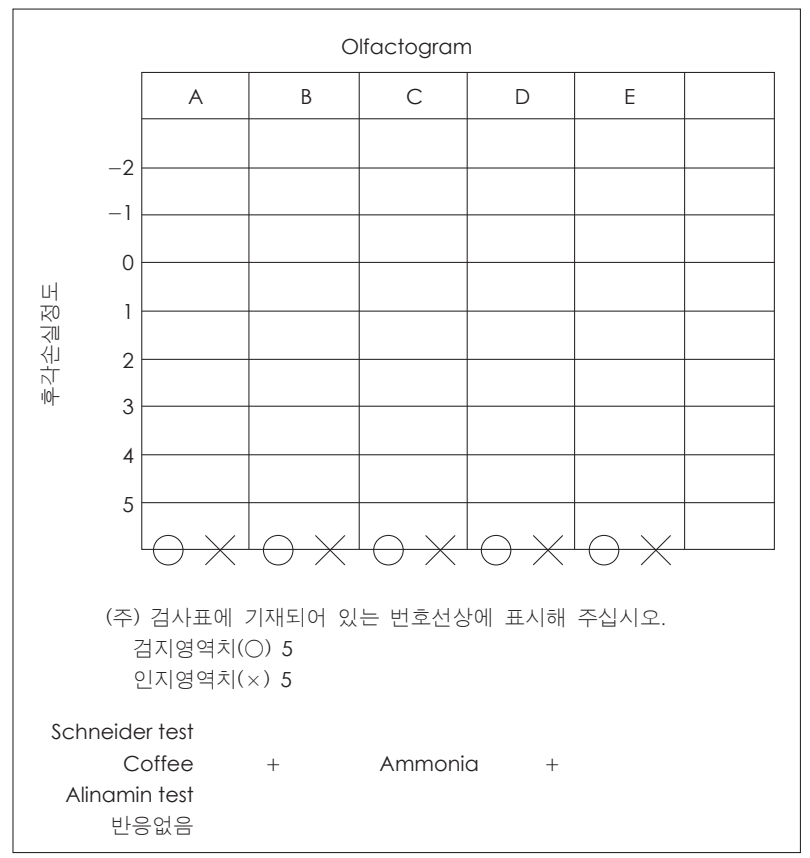

Fig. 1. T\&T olfactometry and the alinamin test reveal the findings of anosmia. The patient was false positive for the Schneider test.
소견이 없었다. 과거력, 현병력에서도 2 개월 전 자연분만 이외 에 특별한 병력은 없었다. 환자의 후각 상태를 파악하기 위해 $\mathrm{T} \& \mathrm{~T}$, 아리나민, 슈나이더 검사를 시행하였다. 환자는 T\&T 검사에서 후각소실을 보였고 아리나민 검사에서는 반응 없었 으며 슈나이더 검사에서 커피 및 암모니아에 양성반응을 보 였지만 특별히 꾀병을 의심할 만한 소견은 보이지 않았다 (Fig. 1). 환자의 이학적 검사상 특이소견은 없었지만 후각소 실의 가장 흔한 원인인 비·부비동염을 감별하기 위해 부비동 전산화 단층촬영을 시행하였다. 부비동 전산화 단층촬영에 서 부비동염을 의심할만한 소견은 보이지 않았고 비강 내에 다른 이상 소견이 보이지 않았으나 뇌기저부 골의 결손 및 두 개저 부위에 뼈가 두꺼워진 양상을 보였다(Fig. 2). 영상의학 과에 정식판독을 의뢰하였고 뇌 내 병변, 특히 후구부위의 뇌수막종이 의심된다는 보고를 받고 뇌 자기공명영상을 촬영 하였다. 뇌 자기공명영상 촬영에서 후구 부위의 뇌수막종이 의심되는 병변이 관찰되었는데 이는 경계가 뚜렷한 $5.7 \times 4.5$ $\times 4.3 \mathrm{~cm}$ 크기의 내부가 균일한 양상으로 보이며 $\mathrm{T} 1$ 강조 영 상에서 저신호 강도로 $\mathrm{T} 2$ 강조 영상에서 고신호 강도로 보이 는 뇌 부종이 동반된 종물이 발견되었다(Fig. 3). 후구 부위 의 뇌수막종으로 의심되어 신경외과로 전과되었으며 이후 뇌 종양 적출술을 시행 받았고 조직검사상 뇌수막종이 확진되
Fig. 2. Preoperative coronal OMU CT scan. The white arrows show a bony defect $(\mathrm{A})$ and hyperosteosis (B).
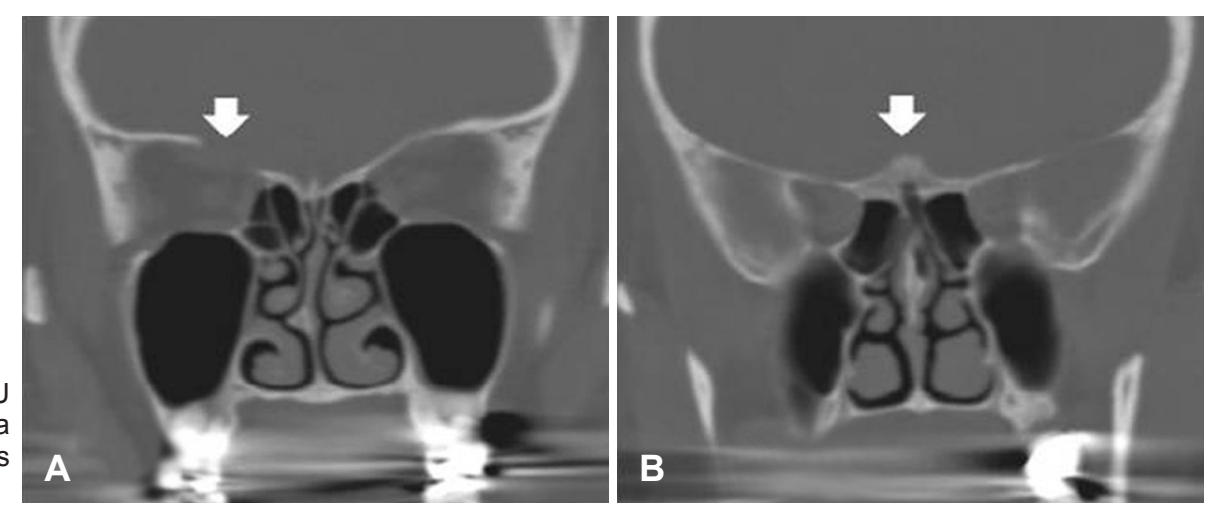
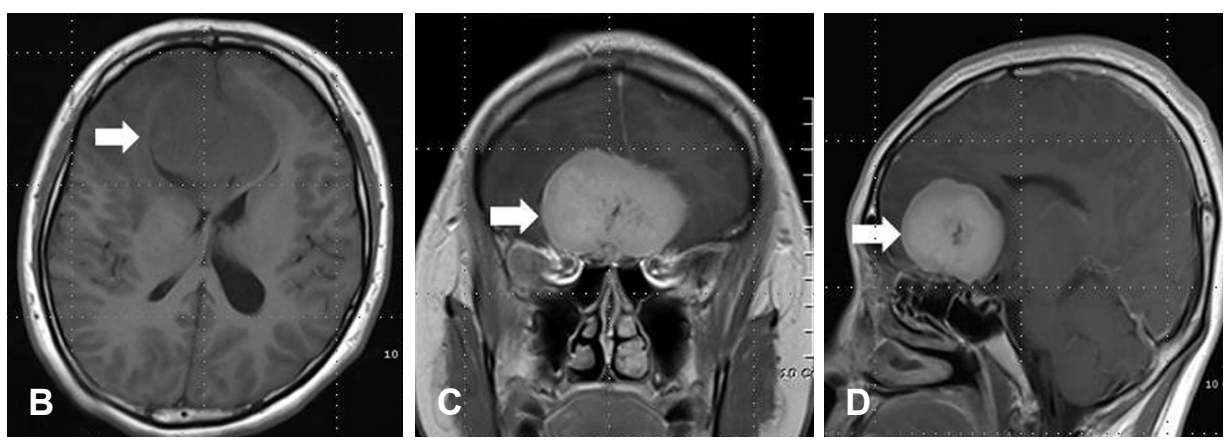

Fig. 3. Preoperative axial view of Gd-DTPA-enhanced MRI. T2-weighted image (A) and T1-enhanced image (B) show that a 5.7 $\times 4.3$ $\mathrm{cm}$ round, extra-axial solid mass with a central cystic portion and well homogenous enhancement in a solid portion with cerebral edema. Preoperative Gd-DTPA-enhanced MRI coronal and saggital view. A white arrow of T1-weighted image (C) shows a broad-based mass on the dura of the lesser wing of the right sphenoid bone, and a T1-weighted image (D) shows solid mass on olfactory bulb. 

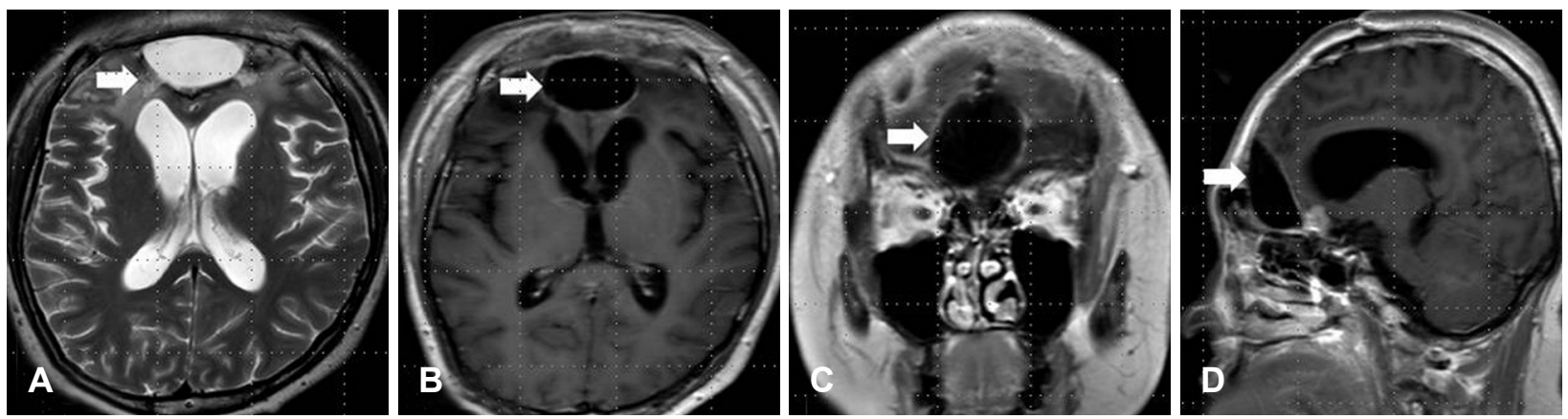

Fig. 4. Postoperative axial view of Gd-DTPA-enhanced MRI. T2-weighted image (A) and T1-enhanced image (B) show gross total resection of the olfactory groove meningioma and encephalomalatic change and disappear brain edema. Preoperative Gd-DTPA-enhanced MRI coronal and saggital view. A white arrow of T1-weighted image (C) and (D) also show gross total resection of the olfactory groove meningioma and encephalomalatic change.

었다. 술 후 2개월 후 촬영 한 뇌 자기공명영상 촬영에서 이전 에 관찰되었던 후구 부위의 종양이 T1 과 T2 강조 영상에서 관찰되지 않았고 주위에 뇌 부종도 사라진 상태다(Fig. 4). 술 후 6개월이 지났지만 환자의 후각소실은 회복되지 않았다.

\section{고 찰}

후각소실의 원인에서 두개내종양은 다른 원인에 비하여 빈도가 적다. 하지만 후각소실을 주소로 내원한 환자에서 두 개내종양의 가능성을 완전히 배제할 수 없다. 뇌수막종은 지 주막 용모의 수막 상피세포에서 기원하며 두개내종양의 $18 \%$, 소뇌 교각부종양의 3 8\%를 차지하고 원발성으로 두개 내에서 발생하는 가장 흔한 종양 중 하나이다. ${ }^{3,4}$ 그 중에서 후구 부위에 발생하는 뇌수막종은 전체 뇌수막종의 약 8 18\% 정도 차지하고 있다. ${ }^{5}$

뇌수막종의 임상적 양상은 비특이적이고 다양하다. 위치 에 따라 나타나는 증상이 다르나 일반적으로 $4 \mathrm{~cm}$ 정도 크 기가 되기 전까지는 특별한 증상이 없어 진단이 어렵다. ${ }^{6}$ 특 히 후구 부위의 뇌수막종은 전두엽 아래쪽에 있으며 전두엽 부위에 이상소견이 발견되면 후각, 인격, 자율신경계 통제 등 여러 가지 문제가 발생할 수 있다. ${ }^{7}$ 그러므로 후구부위에 수 막종은 후각소실도 나타나지만 다른 신경학적 증상이 동반 되는 사례가 대부분이고 후구 부위에 수막종이라도 양측 후 구 부위가 아닌 한측에만 종물이 있을 경우에는 후각소실이 나타나지 않는 경우도 관찰된다. ${ }^{8}$ 본 예에서는 두개내종물에 의한 후각소실 이외에 다른 증상은 보이지 않았다.

진단은 방사선학적으로 전산화단층촬영과 뇌 자기공명영 상촬영이 중요한 단서를 제공하며, 확진은 조직검사를 통해 서 가능하다. 후각검사는 수막종이 생기는 위치에 따라 후구 부위에 발생하는 수막종이라도 한쪽 후구에만 생길 경우는 후각장애가 없을 수 있으므로 두개내종양을 진단하는 데는
진단적 가치가 떨어진다. ${ }^{8)}$ 뇌수막종의 영상학적 특징은 전산 화단층촬영에서 골벽의 파괴 및 골과다증식증을 볼 수 있다. 골벽의 파괴 및 골과다증식증을 볼 때는 뇌 자기공명촬영 보 다 전산화단층촬영이 더 유용하다. 조영 증강된 뇌 자기공명 영상 촬영은 두개 내 파급 정도를 진단하는 데 도움이 되며 $\mathrm{T} 1$ 강조영상에서는 등신호 강도 또는 약간의 저신호 강도를 보이며 T2 강조영상에서는 종양의 혈관분포상태와 석회화에 따라 다양한 신호강도를 보이며 조영제 주입 후 매우 강하고 균질한 조영 증강을 보인다.,10)

감별해야 할 질환으로는 상피성 암종이나 후각 신경 초종 (olfactory neuroblastoma), 골육종, 연골 육종, 혈관종, 림프 종 등이 있으며 이들은 뇌 자기공명영상에서 어느 정도 감별 이 가능할 수 있으나 조직검사를 통한 확진이 필요하다. ${ }^{11}$

치료는 수술적 제거가 일차적인 방법이며 그 외에 보조적 방사선 치료와 항암제 치료를 포함한다. ${ }^{12}$ 완전절제 후의 예 후는 좋은 편이다. 술 후 재발률은 약 $15 \%$ 정도이며, 재발기 간은 평균 5년 정도로 보고되고 있다. 그러므로 대부분의 저 자들은 술 후 약 10 15년 장기간의 추적관찰을 권유하고 있 다. 매년 전산화단층촬영으로 지속적인 추적 관찰이 필요하 다. 가장 흔한 재발의 원인은 불완전한 종괴 제거에 있다.,12)

본 증례는 후각 소실만을 주소로 내원한 환자에서 후각 소실의 흔한 원인인 비·부비동 질환을 배제하기 위하여 조 영 증강 없이 부비동 전산화단층촬영을 시행하여 뇌병변을 확인하기 어려웠다. 그러므로 후각 장애가 있을 시 뇌내 병변 의 가능성이 있으므로 조영 증강 전산화단층촬영이 필요하 며 이후 이상 소견이 발견되었을시 뇌 자기공명영상촬영이 필요하다. 후각장애가 있을 시 다른 신경학적 증상이 없이 후각소실만 나타난 경우는 드물다. 하지만 후각소실만을 증 상으로 내원한 환자에게 완전히 중추성 질환을 배제하기 위 해서 조영 증강 전산화단층촬영 및 뇌 자기공명영상촬영이 필요하다. 


\section{REFERENCES}

1) Black PM. Meningiomas. Neurosurgery 1993;32(4):643-57.

2) Gerber M, Vishteh AG, Spetzler RF. Return of olfaction after gross total resection of an olfactory groove meningioma: case report. Skull Base Surg 1998;8(4):229-31.

3) Persky MS, Som ML. Olfactory groove meningioma with paranasalsinus and nasal cavity extension: a combined approach. Otolaryngology 1978;86(5):ORL714-20.

4) Hoye SJ, Hoar CS Jr, Murray JE. Extracranial meningioma presenting as a tumor of the neck. Am J Surg 1960;100:486-9.

5) McDermott MW, Wilson CB. Meningiomas. In: Youmans JR, ed. Neurological surgery. 4th ed. Philadelphia: Saunders; 1996.

6) Ojemann RG. Olfactory groove meningiomas. In: Al-Mefty O, ed. Meningiomas. New York: Raven;1991. p.383-93.

7) Bogousslavsky J, Caplan L. Stroke syndrome. 2nd ed. United Kingdom, University Press: Cambridge; 2001. p.1848-68.
8) Welge-Luessen A, Temmel A, Quint C, Moll B, Wolf S, Hummel T. Olfactory function in patients with olfactory groove meningioma. $\mathrm{J}$ Neurol Neurosurg Psychiatry 2001;70(2):218-21.

9) Mori S, Kobayashi S, Miki H, Hirakawa E, Haba R, Ohmori M, et al. Extracranial meningioma in the parapharyngeal space. Acta Pathol Jpn 1993;43(3):130-4.

10) Lalwani AK, Jackler RK. Preoperative differentiation between meningioma of the cerebellopontine angle and acoustic neruromausing MRI. Otolaryngol Head Neck Surg 1993;109(1):88-95.

11) Thompson LD, Gyure KA. Extracranial sinonasal tract meningiomas: a clinicopathologic study of 30 cases with a review of the literature. Am J Surg Pathol 2000;24(5):640-50.

12) Maiuri F, Salzano FA, Motta S, Colella G, Sardo L. Olfactory groove meningioma with paranasal sinus and nasal cavity extension: removal by combined subfrontal and nasal approach. J Craniomaxillofac Surg 1998;26(5):314-7. 